\title{
Механизмы образования специальных границ наклона и кручения
}

\author{
С.М. Пещерова ${ }^{1)}$, А.И. Непомнящих ${ }^{1)}$, А.Г. Чуешова ${ }^{1,2)}$ \\ ${ }^{1}$ Институт геохимии им. А.П. Виноградова СО РАН, \\ 664033, г. Иркутск, ул. Фаворского, д.1 "A" \\ ${ }^{2}$ Иркутский государственный университет, 664003, ул. Карла Маркса, д.1 \\ эл.nочта: spescherova@mail.ru
}

DOI 10.34077/RCSP2019-41

В силу того, что границы зёрен оказывают сильное влияние на распределение электрофизических свойств в объеме мультикристаллического кремния (мультикремния), необходимо не только владеть информацией о степени влияния того или иного типа границ на рекомбинацию неравновесных носителей заряда, но и иметь представление об основных причинах формирования различных типов границ в процессе кристаллизации [1]. Кроме того, развитие методов моделирования и свойств границ зёрен предусматривает как можно больше информации о структуре и свойствах границ зёрен, полученной экспериментально. До недавнего времени границы зёрен делили на рекомбинационно активные случайные и специальные границы с низкой рекомбинационной активностью [2]. Специальные границы в кубических кристаллах теоретически изучены хорошо, некоторые из рассчитанных моделей $\sum 3, \sum 5, \sum 7, \sum 9$ и $\sum 13$ b границ с углами разориентации, отличными от $60^{0}$, $36,8^{0}, 38,2^{0}, 38,9^{0}$, соответственно, наблюдали экспериментально [3,4]. Согласно расчетным данным, отклонение угла разориентации сопровождается повышением энергии границы, что означает её повышенную рекомбинационную активность. Наши исследования показали, что рекомбинационная активность $\sum 3$ границ локально может быть выше, чем случайных границ. Прежде всего это связано со структурными параметрами специальной границы, а также причинами её образования. Зёрна со строго определёнными кристаллографическими параметрами могут образовывать специальную границу определенного типа. Эти же параметры регламентируют особенности строения и, следовательно, потенциальную рекомбинационную активность границы. Данная работа посвящена исследованию электрических и структурных свойств специальных границ в мультикремнии. Рассмотрены механизмы образования рекомбинационно активных границ наклона и смешанного типа (наклона и кручения), а также наиболее благоприятных для электрофизических характеристик мультикремния границ кручения.

\section{Лumepamypa}

[1] Kozo Fujiwara. Crystal Growth Behaviors of Silicon during Melt Growth Processes. International Journal of Photoenergy, Volume 2012, 1-16, DOI: 10.1155/2012/169829.

[2] Andreas Stoffers, Oana Cojocaru-Mirédin, Winfried Seifert et al. Grain boundary segregation in multicrystalline silicon: correlative characterization by EBSD, EBIC, and atom probe tomography. Prog. Photovolt: Res. Appl. (2015), DOI: 10.1002/pip.2614.

[3] A. Morawiec. Low-R twist and tilt grain boundaries in cubic materials. Journal of Applied Crystallography (2011). 44, 1152-1156, DOI:10.1107/S002188981104310X.

[4] Ya-Xin Feng, Jia-Xiang Shang, Zeng-Hui Liu et al. The energy and structure of $\left(\begin{array}{lll}1 & 1 & 0\end{array}\right)$ twist grain boundary in tungsten. Applied Surface Science 357 (2015) 262-267, DOI: 10.1016/j.apsusc.2015.08.265. 